\title{
Single-port transgastric access for repeated debridement of infected pancreatic necrotic tissue
}
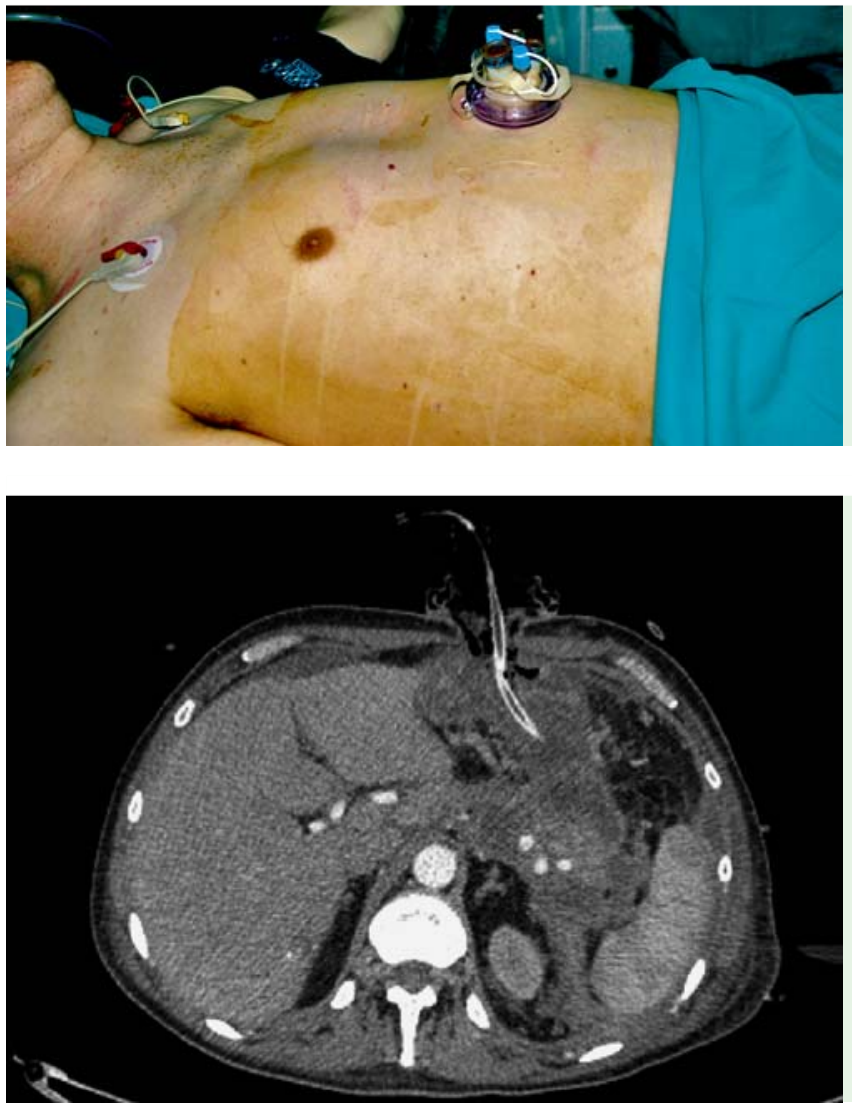

Fig. 2 A computed tomography (CT) scan illustrating drainage of the collection through a drain inserted via TriPort Access System and posterior wall of the stomach.

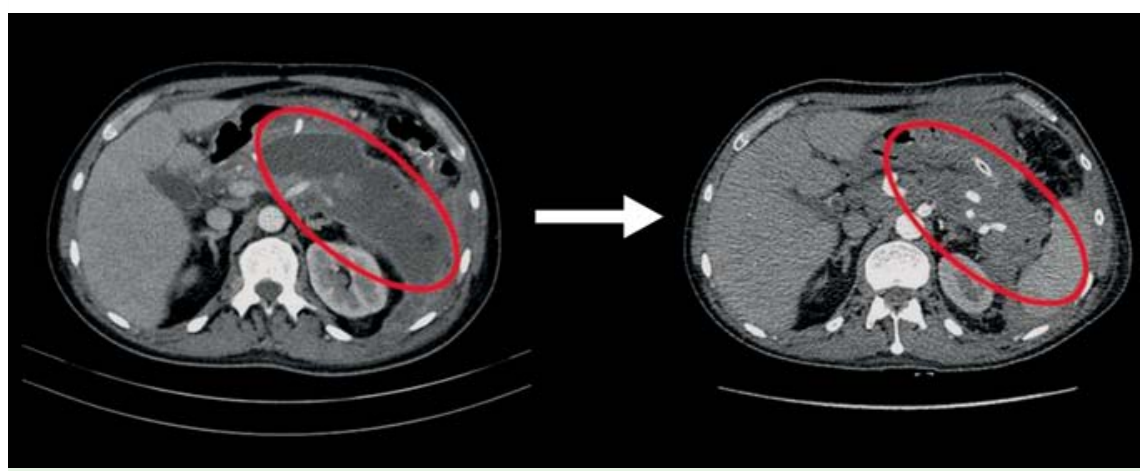

Fig. 4 Computed tomography $(\mathrm{CT})$ scans demonstrating effectiveness of described technique in drainage of infected pancreatic necrotic tissue.

We present a novel technique developed in our institution: repeated single-port transgastric debridement of walled-off pancreatic necrotic tissue using TriPort Access System (Olympus, Warsaw, Poland).

After routine endotracheal intubation, gastric insufflation with a gastroscope is carried out to obtain approximation of the anterior gastric and abdominal walls. Percutaneous gastropexy is then carried out to stabilize the port insertion site. This is followed by a skin and fascial incision $(1.5-2 \mathrm{~cm})$ and opening of the anterior gastric wall (under gastroscopic view). The port introducer is inserted into the lumen of the stomach and the TriPort Access System (port) is securely positioned and fixed as recommended by manufacturer ( $\bullet$ Fig. 1). From this point both anterior abdominal and anterior gastric walls are

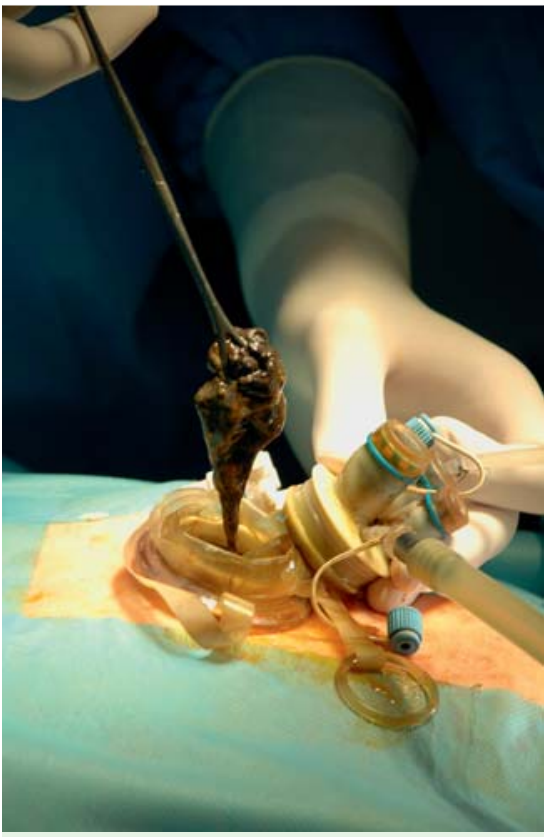

Fig. 3 Debridement of necrotic tissue using open surgery instrumentation through an open cap of the TriPort Access System.

embraced by the port. The laparoscope is introduced and the posterior wall of the stomach is visualized; the gastroscope is retracted. Two 5-mm instruments are introduced: articulating grasper and LigaSure V Sealer/Divider (Valleylab, Covidien, Warsaw, Poland). Next, a 3-4-cm incision is made in the posterior wall of the stomach (optionally under ultrasound guidance) to enable extensive lavage and gentle debridement of the necrotic tissue under direct vision ( Video 1 ). A Flocare tube (Nutricia Polska, Warsaw, Poland) is inserted and a drain is introduced and positioned in the lesser sac for continuous lavage ( Fig. 2). The instruments are removed and the patient transferred to the intensive care unit with the port in place. Repeated explorations are now possible without endoscopic assistance. Opening of the port's cap enables direct debridement with open surgery instrumentation (ه Fig. 3). Continuous lavage is also possible between revisions.

\section{Video 1}

Direct debridement of infected pancreatic necrosis during one of the revisions. 
In summary, the presented innovative technique seems to be an effective approach ( Fig. 4) for the treatment of walled-off pancreatic necrotic tissue in patients with acute pancreatitis. Compartmentalization of the necrotic tissue and extensive communication between the necrotic collection and the stomach have to be balanced against the potential for impaired gastric motility, strictures, or a chronic gastric fistula [1,2]. Studies comparing the feasibility, safety, and efficiency of this technique with other approaches are warranted $[3,4]$.

\section{Competing interests: None}

Endoscopy_UCTN_Code_TTT_1AR_2AI

\section{J. Kobiela, S. Hac, Z. Sledzinski}

Department of General, Endocrine and

Transplant Surgery, Medical University of Gdansk, Poland

\section{References}

1 Babu BI, Siriwardena AK. Current status of minimally invasive necrosectomy for postinflammatory pancreatic necrosis. HPB (Oxford) 2009; 11: $96-102$

2 Friedland S, Kaltenbach T, Sugimoto M, Soetikno R. Endoscopic necrosectomy of organized pancreatic necrosis: a currently practiced NOTES procedure. J Hepatobiliary Pancreat Surg 2009; 16: 266 - 269

3 Rodriguez JR, Razo AO, Targarona J et al. Debridement and closed packing for sterile or infected necrotizing pancreatitis: insights into indications and outcomes in 167 patients. Ann Surg 2008; 247: 294 - 299

4 van Santvoort HC, Besselink MG, Cirkel GA, Gooszen HG. A nationwide Dutch study into the optimal treatment of patients with infected necrotising pancreatitis: the PANTER trial. Ned Tijdschr Geneeskd 2006; 150: $1844-1846$
Bibliography

DOI $10.1055 / \mathrm{s}-0030-1255903$

Endoscopy 2010; 42: E354-E355

(c) Georg Thieme Verlag KG Stuttgart · New York . ISSN 0013-726X

\section{Corresponding author}

Prof. Z. Sledzinski

Department of General, Endocrine and Transplant Surgery

Medical University of Gdansk

7 Debinki Str

PL-80-211 Gdansk

Poland

ichir@gumed.edu.pl 